\title{
La Traducción y la Voz
}

\section{Translation and Voice}

Autor: Omar Lobos

Edição: RUS Vol. 11. No 17

Data: Dezembro de 2020

https://doi.org/10.11606/issn.2317-4765.rus.2020.174145 


\section{La traducción y 1 a voz}

Resumen: La palabra "literatura" remite a la letra, pero, paradójicamente, el espesor emotivo de las palabras que es su materia fundamental solo se manifiesta como resonancia. Aquello "descartado", que es la voz - la voz como sonido, como dicción, como mímica, como identidad -, tiene por su parte una relevancia extraordinaria en la configuración de la literatura rusa en general y en la de autores como Gógol, Dostoievski y Platónov en particular. El artículo ofrece una pequeña historización de la configuración de la lengua literaria rusa, caracteriza algunos aspectos estilísticos relacionados con la voz en autores emblemáticos, para reflexionar luego sobre la importancia de tomar en cuenta tales aspectos a la hora de traducir.
Abstract: The word "literature" refers to letter, but, paradoxically, the emotional dimension of words, its basic material, only manifests itself as resonance. The voice, that which is "discarded" - the voice as sound, as diction, as mimicry, as identity- has itself an extraordinary importance for the configuration of the Russian literature at large and for the literature of authors such as Gogol, Dostoevsky and Platonov in particular. This paper offers a brief historical review of the development of the Russian literary language and characterizes some stylistic aspects related to the voice of these emblematic authors so as to finally reflect on the importance of taking such aspects into account when translating.

Palabras clave: Voz; Ritmo; Traducción; Gógol; Dostoievski; Platónov Keywords: Voice; Rythm; Translation; Gogol; Dostoevsky; Platonov 
* Docente de la cátedra de Literaturas Eslavas de la Facultad de Filosofía y Letras de la Universidad de Buenos Aires (UBA), así como de Lengua Española en la Universidad Nacional de Lanús. Miembro fundador de la Sociedad Argentina Dostoievski.calfucur@ yahoo.com.ar. https://orcid.org/ 0000-0001-8802-8232

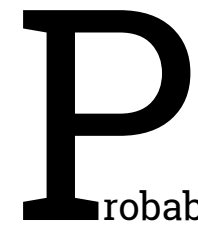

robablemente en todos los escritores exista una correspondencia o conexión entre lo que escriben y su propia voz: la respiración determinando los períodos sintácticos y el ritmo, el volumen natural, el registro, el color, la entonación, su carácter más o menos digresivo, su nerviosismo o parsimonia, el propio léxico, áspero, tierno, enfático, lacónico, e incluso la mímica gestual que acompaña a esa voz. Espíritu, al fin y al cabo, viene de respiración, es respiración. La escritura fonética es, por supuesto, subsidiaria de la voz; no obstante lo cual ha pugnado por autonomizarse $y$, finalmente, prescindir de esta. La propia palabra "literatura" remite a la letra, pero, paradójicamente, el espesor emotivo de las palabras que es su materia fundamental solo se manifiesta como resonancia. Esto es, la voz vuelve para recobrar lo que es suyo.

Desde que comencé mi tarea de traductor, seguir la voz del autor, en su esencia musical (vibración, color, entonación, aliento, jmímica!), ha sido una guía esencial, a la vez que un desvelo. Tal vez porque comencé a traducir muy tempranamente respecto de mi conocimiento del ruso, forzado por amigos míos cantantes de música de cámara que estudiaban romanzas rusas (de Chaikovski, de Rajmáninov) y me pedían que les tradujera la "letra". La "letra" muy a menudo eran célebres versos de Pushkin, Lérmontov, Fet, Alexéi Tolstói y otros grandes poetas), y a mí, a pesar del cometido práctico de esa traducción - enterarse fundamentalmente del contenido que se está cantando - no me complacía si no los ajustaba también estilísticamente $y$, sobre todo, rítmicamente.

Andando el tiempo, se me propuso la primera traducción profesional para una nueva colección de literatura clásica de la editorial con la que trabajaba - y trabajo - en diversos temas. Cuando mi jefe me dice que debo traducir Crimen y castigo, de Dostoievski, mi reacción fue de espanto y dije que era 
imposible, que no podía hacerlo, porque no tenía experiencia, porque no me sentía a la altura del desafío. El editor no es una persona que acepte fácilmente una negativa, de modo que me dijo que yo no tenía otra opción que sentarme a traducir, que él me compraría diccionarios, todas las versiones ya traducidas de la obra que yo necesitara y que, en fin, en unos meses me llamaría a ver cómo iba la tarea. Con el corazón atribulado conseguí el original y puse manos a la obra. Trabajé mucho, consulté a amigos rusos y a profesores nativos de lengua y literatura rusa, terminé la traducción, al cabo de intensos ocho o nueve meses. Pero el caso es que, al quedarme a solas con mi versión, esta me pareció horriblemente despojada de todo encanto literario. Si bien las otras ediciones con las que la había comparado durante el trabajo no me gustaban en muchos aspectos, era indiscutible que "se leían" bien. No era así en mi caso, donde la prosa resultaba tosca, desmañada y sin gracia. No se trataba de problemas de traducción, ni de redacción, sino de algo que yo no conseguía determinar. Resolví que tenía que juntar fuerzas para decir a mi editor que no podría entregarle ese trabajo, que no estaba bien y que seguramente yo debería acumular bastante experiencia en el métier para volver a encarar una obra de esa magnitud. No obstante, me seguía desvelando la razón por la cual mi traducción fluía mal, es decir, no resultaba eufónica, y comencé a comparar el primer párrafo en el original - una sola frase de cuatro líneas y media, un solo arco entonacional - con mi resultado, y descubrí que este no repetía ese efecto, y que era eso lo que me disgustaba. De modo que me puse a realizar todos los reacomodos necesarios para que mi texto se leyera - se oyera, se respirara - igual que el texto ruso. Y allí empezó una feliz nueva aventura: reponer la dicción del original en mi versión. Tras un año más de trabajo pude entregar mi traducción, bastante contento y tranquilo con ella.

A partir de allí, sentir hablar y respirar el original es lo que hilvana fundamentalmente mi trabajo. (Dicho método me revelaría luego que buena parte de mis desavenencias con las traducciones de otros consistía y consiste en un presumido desdén en ellas por el sonido y la voz). Esto tomando además 
en cuenta que la literatura rusa es, por razones que sintetizaré a continuación, una literatura forjada fundamentalmente en la voz.

Para los que formamos parte de lenguas históricas con una larga tradición escrita, como es el caso del castellano, parecerían - en términos generales - estar muy establecidas, muy repartidas las formas que corresponden a la oralidad o a la escritura. Puede pensarse que, en ese sentido, nuestra lengua escrita se vino construyendo como tal por lo menos desde que el rey Alfonso X, a fines del siglo XIII, oficializara el castellano para la redacción de los documentos públicos (aunque los primeros testimonios de la escritura en castellano se remonten al siglo XI) y diera impulso a la confección de obras eruditas en la lengua vernácula, parangonándola así con las consideradas lenguas cultas. Esa jerarquización del castellano como lengua escrita propiciada por el rey sabio dio origen también al español literario. A partir de allí, empeños siempre renovados irían perfilando de determinado modo la escritura de la lengua que devendría española con los Reyes Católicos, que sufriría los latinazos del Renacimiento, se italianizaría con la corte de Carlos V en Nápoles, se vería aliviada de melindres por los nuevos aires de la Contrarreforma, se extendería y padecería en América con felicidad (Menéndez Pidal, 1945).

La literatura rusa ha realizado, por razones culturales e históricas, un camino diferente del de las demás literaturas del Occidente europeo. Primero porque sólo puede ser considerada una literatura "occidental" a partir del siglo XVIII, con las reformas de Pedro el Grande, que forzaron la europeización de Rusia en todos sus niveles. Solamente a partir del clasicismo ruso puede hablarse de la literatura como una institución diferenciada, con su especificidad y liberada de la tutela de la Iglesia, y permeable de allí en más a las tendencias y movimientos literarios que surjan en la Europa occidental (neoclasicismo, romanticismo, realismo, simbolismo, vanguardia). Segundo, porque dicha europeización atentó contra todo el acervo cultural ruso (incluida toda la literatura rusa antigua) $\mathrm{y}$, en el mismo impulso, contra la lengua rusa misma, subestimada por "bárbara" en el ímpetu transformador que intentaba 
modernizar el viejo y gigantesco país. Contra la prevalencia de la lengua natal, desembarcarían en Petersburgo - nueva sede de la corte y símbolo tremendo de la Nueva Rusia - los ingenieros alemanes, los arquitectos franceses e italianos, y con ellos sus lenguas "civilizadas" y prestigiosas, que forzarían el retraimiento del idioma vernáculo en diversos aspectos. Se entorpece la lengua, y se endurece la mano para escribir en ruso. El neerlandés y el alemán proveen los precisos términos técnicos que dominan la ciencia y la tecnología. El francés y su articulación meliflua se ajustan a las aspiraciones de buen tono de la nueva clase cortesana; se alfabetiza en francés; y en francés se redactan los ukaces del zar.

Pero el clasicismo ruso deparó también un hombre colosal como Mijailo Lomonósov (1711-1765), que, en su tarea de sistematizar y prestigiar la lengua natal, defenderla de la incorporación desordenada y arbitraria de voces extranjeras y además legislar sobre su uso literario, encontró un elemento regulador en el eslavo eclesiástico, la lengua docta, el "latín" ruso. A posteriori, la autoridad de Lomonósov y su legado hizo que los escritores del postclasicismo tuvieran que luchar contra la rigidez de esa lengua literaria, de espíritu aristocrático y arcaizante, establecida por él. Aparecerían los cultores del "nuevo estilo", que aspiraban a desarrollar una prosa moderna y mundana, de salón, a imitación del modelo de la prosa francesa. El resultado de esta nueva modalidad fue una lengua convencional y estrecha, donde dos tercios del ruso real no eran admitidos. De manera que faltaba la lengua flexible, segura de sí misma, viva de ímpetu. Y el llamado a despertar esa lengua e incorporar en la literatura el acervo popular y folklórico ruso fue Alexandr Pushkin, considerado por ello el padre de las letras rusas modernas. Así, en la obra de Pushkin se combinaría el bagaje de la tradición letrada con la lengua abrevada en las fuentes orales - y los estilos a ella ligados -, donde el ruso se había preservado vivo, vital, rico e intenso. Esta lengua, que acabaría de irrumpir ya sin prejuicios de la pluma de Nikolái Gógol, es una lengua fundamentalmente forjada en la oralidad. A esa modalidad Gógol subordinaría incluso registros de naturaleza escrita o libresca (como los esti- 
los de la burocracia estatal, el retoricismo de cuño docto o las formas de trato social de "buen tono"), convirtiéndolos fundamentalmente en efectos mímicos y contribuyendo con ellos a la ilusión de cierta proximidad "escénica", oral, de los textos.

Los formalistas refieren a estas marcas orales supervivientes en la letra o adoptadas por ella con el nombre de skaz. El skaz no solamente remite a un tipo de registro (oral, pictórico, incluso con una inherente orientación cómica), sino a un tipo de estructuración que remedaría la dicción espontánea ("En el Departamento de... no, mejor no decir en qué departamento, no hay nada más enojoso que...", comienza "El capote", de Gógol). En el skaz el lenguaje es manipulado de otra manera, y la voz, la voz como aliento y como sonido, es un elemento fundamental en el tipo de expresividad que se despliega. Borís Eichenbaum fue de los primeros que llamó la atención sobre esta modalidad, retomando la idea - para él muy fecunda - de algunos lingüistas alemanes de desarrollar una "lingüística acústica" (Ohrenphilologie), en contraste con la "visual" ( $\mathrm{Au}$ genphilologie):

Siempre hablamos de la literatura, del libro, del escritor. La cultura escrituraria impresa nos ha acostumbrado a la letra. Librescos al fin, la palabra solamente la vemos; siempre es para nosotros algo insolublemente ligado con la letra. A menudo olvidamos por completo que la palabra por sí misma no tiene nada en común con la letra, que es una actividad viva, en movimiento, formada por la voz, la articulación, la entonación, a las que se unen además los gestos y la mímica. ${ }^{1}$

Al hablar de la escripción (sic) de un texto de naturaleza oral, Roland Barthes refiere a las adaptaciones que se le hacen en ese tránsito, alejándolo del destinatario al quitar las marcas de búsqueda del lenguaje que la revisión y la reflexión permiten subsanar cuando se transcribe, por el carácter mediato del encuentro con el lector; en definitiva, señala Barthes, en tales operaciones es hurtado el cuerpo (Barthes, 2005). En el caso de la lengua rusa, el lenguaje escrito forjado en la oralidad mantuvo - a diferencia de lo que observa el teórico francés - los rasgos fundamentales de este origen. Es por ello que produce

1ЭЙХЕНБАУМ, 1924: 152 
un efecto de lectura por el cual la prosa escrita rusa "se oye", antes que "leerse". Tenemos autores que dictan sus libros, como Gógol o Dostoievski, o bien se hallan casos como el de Vladímir Maiakovski, que crea sus poemas para ser declamados, y conforme con esa noción hace sus búsquedas rítmicas, entonacionales y la de sus rimas mismas: esto es, los poemas de Maiakovski riman mejor oídos que en la lectura silenciosa, el poeta puede hacer rimar, por la acentuación y pronunciación rusa - que absorbe en general las vocales átonas -, palabras que, a la vista, no parecen hacerlo.

Nuestra hipótesis es que estas peculiaridades de la lengua literaria rusa en general a menudo no son tomadas en cuenta en nuestras traducciones, que en general eligen acomodarse a los muelles modos de la prosa castellana (cimentada por otra tradición, otro devenir) y relegando a los deshechos "fatales" de toda traducción esos rasgos poderosos y esencialmente estilísticos de la lengua rusa. Es la llamada por el traductólogo francés Antoine Berman "orientación etnocéntrica e hipertextual" de la traducción.

El poeta y traductólogo francés Henri Meschonnic (hijo de judíos rusos) propone por su parte una orientación poética, la cual reclama la superación del signo lingüístico - elemento discontinuo por excelencia y en el cual está centrada toda la teoría occidental del lenguaje - por parte del ritmo - manifestación de una continuidad - como condición del continuo cuerpo-poema. Así, Meschonnic entiende el ritmo como "la organización del movimiento de la palabra en el lenguaje" (Meschonnic, 2009: 55), que impone un escuchar "el lazo entre ritmo, sintaxis y prosodia, que corre a través de todas las palabras" (ídem: 113). Ciertamente, elementos semejantes exceden el signo lingüístico: el cuerpo, la voz (la bucalidad de la voz, como dice Meschonnic), los acentos, cobran lo suyo, hay allí una confluencia entre el poema y el teatro que sitúa al traductor absolutamente en otra perspectiva: la perspectiva de la voz, como expresión de un cuerpo soporte de una rítmica.

El filósofo esloveno Mladen Dolar, en su libro Una voz y nada más, analiza este fenómeno humano desde diversas discipli- 
nas: la lingüística, la metafísica, la física, la ética, la política, ámbitos donde la voz se encuentra tensada por una suerte de paradoja: la de tener en todos ellos una participación obligada y ser a la vez inasible tanto en su esencialidad como en los fundamentos de su pertinencia (lo que en cierto modo la volvería "descartable"). Así, escuchamos la voz en el lenguaje, pero para la lingüística es solo un medio para llegar al significado, es un fantasma, una "imagen acústica". Es la deriva de la noción aristotélica de phoné semantiké (voz significativa), que solo aspira al logos. ¿Y qué pasa con los "deshechos" de ese trámite? "Los sonidos", dirá Dolar, "esos intrusos que nadie invitó y que parecen cargar misteriosamente un sentido en sí mismos, independientemente de lo que se quiera expresar, excederán lo que intentes decir" (Dolar, 2007, 174). Es aquí entonces donde propone trazar una línea entre "oír" y "escuchar", que es a la vez una línea entre el significado y el sentido:

oír es ir tras el significado, la significación que puede deletrearse lingüísticamente; escuchar es, más bien, ir en procura del sentido, algo que se anuncia en la voz más allá del significado [...] escuchar implica una apertura hacia un sentido que es indecidible, precario, elusivo y que se pega a la voz ${ }^{2}$.

Sobre esto indecible, precario, elusivo y pegado a la voz, se construye - a mi juicio - buena parte de todo lo que llamamos literatura. Sobre esto se construye, particularmente y para ir a nuestro tema, toda la obra de Nikolái Gógol, de cuyo capote "salieron" todos los escritores rusos, según la famosa frase atribuida a Dostoievski. El discurso gogoliano, nos dice Borís Eichenbaum en su famoso artículo "Cómo está hecho 'El capote"', está construido sobre una "semántica fónica", donde el carácter sonoro se vuelve significativo (Эйхенбаум, 1918). Esto es, se trata de palabras, partículas y frases concebidas fundamentalmente como pronunciación, y que de esto extraen su mayor carga semántica. Por ejemplo, el relato sobre "por qué se malquistó Iván Ivánovich con Iván Nikíforovich" (de 1834) está basado en puros recursos interjectivos, y poco o nada hay más allá de estos, de modo que si alguien preguntara de qué trata el relato, bien podría respondérsele que trata de jah!, joh!, ¡eh!, juf! Baste como muestra el comienzo: 
¡Glorioso abrigo el de Iván Ivánovich! ¡Excelentísimo! ¡Y los detalles de astracán! ¡Qué delirio ese astracán! ¡Gris azulado y nevado! ¡No sé lo que apuesto a ver si alguien encuentra uno así! Fíjense, por Dios, especialmente si él se pone a hablar con alguien, fíjense de costado: jes una delicia! No se puede describir: ¡terciopelo!, ¡plata!, ¡fuego! ¡Señor mío y Dios mío! ¡San Nicolás Milagroso, siervo de Dios!, ipor qué no tengo yo un abrigo así!... ${ }^{3}$

Signos de exclamación encerrando cada oración, invocaciones a Dios y los santos y giros hiperbólicos rezumando por todo el texto. ¿Y todo para hablar de qué?: ¡del abrigo de uno de los personajes! Detalle que, por otra parte, no tiene ni tendrá ninguna relevancia "argumental". Todo el relato está construido sobre este principio interjectivo. Incluso la peripecia del cuento se da a partir de una interjección, un insulto (que por otra parte es sólo percibido como tal por el "agredido" y no tanto por quien lo suelta, que siempre utiliza palabras gruesas), cuando uno de los dos amigos, tan pero tan incomparablemente amigos, fastidiado, trate al otro de "iganso!".

Gógol está todo en la voz, y así parecía comprenderlo él mismo. El joven Iván Turguéniev fue testigo de una visita de Nikolái Vasílievich a los ensayos de su pieza "El inspector", que por alguna razón no prosperaban. El actor principal lo había convocado para que los ayudara en la comprensión y el modo de encararla, y Gógol simplemente tomó el texto y se puso a leer:

Leía Gógol excelentemente... [...] me impactó por la extraordinaria simpleza y lo contenido de su manera, la sinceridad grave y al mismo tiempo ingenua, que era como si no le importara si había aquí oyentes y qué era lo que pensaban. Parecía que Gógol solo se preocupaba por cómo penetrar en un elemento que para él mismo era nuevo, y cómo transmitir más fielmente su propia impresión. El efecto resultaba fuera de lo habitual, particularmente en los pasajes cómicos, humorísticos; no había posibilidad de no reírse, con una risa buena, saludable; y el culpable de todo este regocijo,

\footnotetext{
3 Славная бекеша у Ивана Ивановича! отличнейшая! А какие смушки! Фу ты, пропасть, какие смушки! сизые с морозом! Я ставлю бог знает что, если у кого-либо найдутся такие! Взгляните, ради бога, на них, - особенно если он станет с кем-нибудь говорить, - взгляните сбоку: что это за объядение! Описать нельзя: бархат! серебро! огонь! Господи боже мой! Николай Чудотворец, угодник божий! отчего же у меня нет такой бекеши!.. (Гоголь, 2009, 491) (Todas las traducciones de textos literarios son mías. OL).
} 
sin inmutarse por la común diversión y como asombrándose interiormente de ella, seguía sumergiéndose más y más en el tema, y solo cada tanto, en los labios y alrededor de los ojos, trepidaba apenas perceptible la sonrisita maliciosa del maestro. Con qué perplejidad, con qué estupefacción pronunció Gógol la célebre frase del alcalde sobre las dos ratas (al comienzo mismo de la obra): "iLlegaron, husmearon y se las tomaron!". Incluso nos recorrió lentamente con la mirada, como pidiendo una explicación de un hecho tan asombroso. Solamente allí comprendí de qué modo en general poco fiel, superficial, con qué deseo solamente de hacer reír cuanto antes, se interpreta habitualmente sobre el escenario "El inspector". 4

¿Por qué es graciosa esa voz, por qué el mismo texto, las mismas palabras que repetían los actores, se vuelven inteligentes, penetrantes, cómicas, en el hilván de esa determinada voz? ¿No hay en esa escena un espejo en el que podemos mirarnos los traductores, para evitar devenir en malos repetidores de palabras vaciadas por nosotros mismos? En la prosa de Gógol, además, el hálito vivificador, escénico, de la voz toca incluso a los objetos inanimados, como las célebres puertas cantantes de la casa de Afanasi Ivánovich y Puljeria Ivánovna, terratenientes de antaño, que gimen lastimeras para quien sepa oírlas: "icielos, me congelo!", o los muebles de la sala de Sobakiévich, todos ellos "del natural más pesado e intranquilo", que parecen decir cada uno: "YYo también soy Sobakiévich!" (Гоголь, 1993: 89) [el destacado es nuestro]. O la animización estremecida y ominosa que late en el jardín de Pliushkin:

Un viejo, amplio jardín que se estiraba por detrás de la casa, que salía más allá de la aldea y luego se perdía en el campo, cubierto de hierba y de maleza, parecía dotar él solo de frescura a este amplio caserío y era lo único totalmente pintoresco en su artística desolación. Como nubes verdes e irregulares cúpulas de hojas trepidantes yacían unidas en el horizonte del cielo las cimas de árboles crecidos en libertad. El colosal tronco blanco de un abedul, privado de su parte superior, rota por un temporal o una tormenta, se elevaba de esta espesura verde y se torneaba en el aire como una fulgurante y correcta columna de mármol; su oblicua fractura puntiaguda, con la que terminaba hacia arriba en lugar de

4 ТУРГЕНЕВ, 1952: 535-536 
capitel, se oscurecía sobre su blancura nívea como un gorro o un pájaro negro. El lúpulo, sofocando en lo bajo arbustos de saúco, serba y avellano y recorriendo luego por encima toda la empalizada, se lanzaba finalmente hacia arriba y envolvía hasta la mitad el quebrado abedul. Alcanzada su mitad, de allí se descolgaba él hacia abajo y empezaba ya a prenderse de las cimas de otros árboles o pendía en el aire, enroscando en anillos sus finos ganchos tenaces, mecidos levemente por el aire. En partes se abrían las verdes espesuras iluminadas por el sol, y dejaban ver entre ellas una cavidad no iluminada, entreabierta como oscuras fauces; estaba toda envuelta por la sombra, y apenas asomaban en la negra hondura un angosto senderito fugitivo, unas barandillas derruidas, una glorieta bamboleante, el decrépito tronco lleno de oquedades de un sauce, un canoso jinjolero, como una cerda espesa perforando el sauce con sus secos por el enmarañamiento, confundidos y entrecruzados gajos y hojas, y, finalmente, una joven rama de arce, que extiende desde un lado sus verdes garras-hojas, bajo una de las cuales penetrando Dios sabe de qué modo, el sol la convirtió de golpe en ígnea y trasparente, maravillosamente fulgurante en esta espesa oscuridad. A un costado, en el borde mismo del jardín, algunos crecidos más alto que otros árboles álamos temblones elevaban inmensos nidos de corneja en sus cimas trepidantes. En algunos de ellos, arrancadas y no completamente desgajadas ramas colgaban hacia abajo con sus hojas secas... ${ }^{5}$ [los destacados son nuestros] $]^{6}$

\footnotetext{
5 ГОГОЛЬ, 1993: 105-106

6 Старый, обширный, тянувшийся позади дома сад, выходивший за село и потом пропадавший в поле, заросший и заглохлый, казалось, один освежал эту обширную деревню и один был вполне живописен в своем картинном опустении. Зелеными облаками и неправильными трепетолистными куполами лежали на небесном горизонте соединенные вершины разросшихся на свободе дерев. Белый колоссальный ствол березы, лишенный верхушки, отломленной бурею или грозою, подымался из этой зеленой гущи и круглился на воздухе, как правильная мраморная сверкающая колонна; косой остроконечный излом его, которым он оканчивался кверху вместо капители, темнел на снежной белизне его, как шапка или черная птица. Хмель, глушивший внизу кусты бузины, рябины и лесного орешника и пробежавший потом по верхушке всего частокола, взбегал наконец вверх и обвивал до половины сломленную березу. Достигнув середины ее, он оттуда свешивался вниз и начинал уже цеплять вершины других дерев или же висел на воздухе, завязавши кольцами свои тонкие цепкие крючья, легко колеблемые воздухом. Местами расходились зеленые чащи, озаренные солнцем, и показывали неосвещенное между них углубление, зиявшее, как темная пасть; оно было все окинуто тенью, и чуть-чуть мелькали в черной глубине его: бежавшая узкая дорожка, обрушенные перилы, пошатнувшаяся беседка, дуплистый дряхлый ствол ивы, седой чапыжник, густой щетиною вытыкавший из-за ивы
} 
¿Por qué resulta "ominosa" (unheimlich) esta descripción? En principio, vemos que la animización corre sobre todo por cuenta de los verbos, que le imprimen una energía latente y pronta a rebosar, pero también contribuyen con lo suyo las hojas trepidantes, el tronco colosal, la columna fulgurante, el temporal y la tormenta (que han arrancado la copa), el lúpulo reptante, el senderito fugitivo: temblor, fuerza, destellos, transfiguraciones. Y qué diremos de la sintaxis extendida y tensada por aclaraciones, con sus sustantivos demorados por la anteposición y acumulación de los adjetivos. No obstante, hay algo inerte y estremecedor en ese jardín vivo, y es el silencio. Nada murmura allí. No hay pájaros, ni siquiera viento o brisa, a lo sumo sibila en la aliteración de las eses (como en el original las sibilantes rusas sha y scha). Pável Ánnienkov, que fue copista de Gógol en Roma en 1841, al referir el modo en que este le dictaba los capítulos de Almas muertas, "con voz penetrada de pensamiento y sentimiento concentrado", recuerda particularmente este pasaje del jardín:

Aún con mayor fuerza se expresó el sentimiento de la autosatisfacción autoral en el capítulo donde se describe el jardín de Pliushkin. Nunca antes el pathos del dictado, recuerdo, había alcanzado tal altura en Gógol, conservando toda la naturalidad artística, como en este pasaje. Gógol incluso se levantó del sillón (se veía que la naturaleza que describía pasaba en este momento ante sus ojos) y acompañaba el dictado con orgulloso y en cierto modo imperativo gesto.?

Señala Meschonnic que el traductor debe traducir lo que el poema hace más que lo que el poema dice, "porque no se traduce una lengua, sino lo que un poema le hace a su lengua; por consiguiente, hay que inventar en la lengua de llegada equivalencias de discurso: prosodia por prosodia, metáfora por metáfora, calambur por calambur, ritmo por ritmo" (ídem: 60). Pero

иссохшие от страшной глушины, перепутавшиеся и скрестившиеся листья и сучья, и, наконец, молодая ветвь клена, протянувшая сбоку свои зеленые лапы-листы, под один из которых забравшись Бог весть каким образом, солнце превращало его вдруг в прозрачный и огненный, чудно сиявший в этой густой темноте. В стороне, у самого края сада, несколько высокорослых, не вровень другим, осин подымали огромные вороньи гнезда на трепетные свои вершины. У иных из них отдернутые и не вполне отделенные ветви висели вниз вместе с иссохшими листьями... (Гоголь, 1993, 105)

7 ГОГОЛЬ, 1952: 270 
a mí me preocupan no tanto esas correspondencias tomadas por separado, es decir, salir a la pesca de efectos sonoros para tratar de replicarlos, sino aventurarme a través de todo ello hacia la voz del autor como cifra última del sentido del texto todo.

Vladímir Nabókov impugna al Dostoievski novelista a la vez que concede al escritor talento para el teatro. Me cuesta comprender la diferencia. Dostoievski es teatral por varias razones. La más recurrida es la articulación de la mayoría de sus obras en "escenas" de encuentros entre personajes, cuyos dramas personales e interpersonales se van desarrollando como si fuera en presencia del lector/espectador y a través de sus propios enunciados, sin injerencia de una voz narrativa que se alce por encima del conjunto (ya se ha hablado demasiado del dialogismo y la polifonía en Dostoievski). De ello se deriva la fuerte caracterización lingüística que sus personajes tienen (sociolectal, fundamentalmente), y que las más de las veces se contagia a la voz narrativa, que no necesariamente tiene el mismo registro ni la misma orientación axiológica de lo que dicen aquellos, configurándose así como "arena de un encuentro y lucha de dos entonaciones, dos puntos de vista, dos discursos"8.

No obstante, mi inquietud aquí es cómo hablan los textos dostoievskianos en general, más allá de las marcas lingüísticas pictóricas que puedan caracterizar al narrador y a los personajes, es decir, cómo habla Dostoievski en sus obras. En principio, el verbo "hablar" implica per se una presencia, así como la escritura representa el eco de una ausencia. Dostoievski habla, dicta, y su taquígrafa anota lo que él pronuncia; de allí, insistimos, se deriva buena parte de esa cualidad escénica de sus obras, y se configura el estilo: es una prosa que hace la ilusión de conformarse según los principios del skaz, el discurrir según la dicción espontánea, que expresa incluso en acto la búsqueda que el lenguaje hace del pensamiento y/o la lucha del pensamiento por encontrar su expresión en el lenguaje. Por eso los largos párrafos, saturados de aclaraciones

8 VOLÓSHINOV, 2009, 212 
que interrumpen el normal flujo sintáctico, los recurrentes adverbios modalizadores, las repeticiones enfáticas, como si el autor estuviera representándose la escena y esforzándose en recrear con la mayor exactitud posible lo que él mismo está viendo ante sus ojos:

En uno de los vagones de tercera clase, desde el aclarar, se vieron sentados uno frente a otro, junto a la ventanilla, dos pasajeros, ambos gente joven, ambos ligeros de equipaje, ambos vestidos poco elegante, ambos con fisonomías bastante notables y ambos con deseos, finalmente, de entrar en conversación el uno con el otro. Si ambos dos hubieran sabido qué había en particular de notable para cada uno en el otro en este momento, por supuesto se habrían asombrado de que tan extrañamente el acaso los hubiese sentado uno frente al otro en un vagón de tercera clase del tren Petersburgo-Varsovia. (El idiota, parte I, capítulo I) ${ }^{9}$

Es cierto que los artículos y las preposiciones en castellano vuelven casi perifrásticas algunas económicas construcciones del ruso, pero igualmente resulta claro que Dostoievski pareciera estar luchando contra la fatal linealidad del lenguaje, necesita moldearlo de otra manera, de modo tal que quepa en él todo lo que simultáneamente satura ese instante, esa imagen estática y especular de los dos hombres sentados en un vagón. Y toda esa actualidad está acentuada en el párrafo por el demostrativo de "en este momento" (que en su pereza la traducción castellana tendería a convertir en "en ese momento"). ${ }^{10}$

\footnotetext{
9 В одном из вагонов третьего класса, с рассвета, очутились друг против друга, у самого окна, два пассажира - оба люди молодые, оба почти налегке, оба не щегольски одетые, оба с довольно замечательными физиономиями и оба пожелавшие, наконец, войти друг с другом в разговор. Если б они оба знали один про другого, чем они особенно в эту минуту замечательны, то, конечно, подивились бы, что случай так странно посадил их друг против друга в третьеклассном вагоне петербургско-варшавского поезда. (Достоевский, 2014, 5)

10 En nuestra tesis sobre la lengua literaria rusa, hemos analizado el efecto de actualidad que producen también los deícticos rusos en ejemplos como: "Aunque Iván Fiódorovich había dicho ayer [...] que mañana se irá, al acostarse anoche a dormir recordaba muy bien que en ese momento ni siquiera pensaba en la partida" (Хотя Иван Федорович и говорил вчера [...], что завтра уедет, но, ложась вчера спать, он очень хорошо помнил, что в ту минуту и не думал об отъезде...) (Достоевский, 2005: 386).
} 
Como la de Gógol, la voz de Dostoievski se manifiesta siempre "penetrada de pensamiento y sentimiento concentrado", solo que a esto hay que agregar otro elemento no menos importante que la determina, y es la tensión - a veces insoportable e irritante - por la densificación del tiempo, siempre acuciante para sus personajes. Y es que, contra la concepción extensiva del tiempo que domina la novela decimonónica, el tiempo en las grandes novelas de Dostoievski sorprende por su intensividad. Sus argumentos se despliegan en períodos llamativamente breves (diez días en Crimen y castigo, tres o cuatro en Los hermanos Karamázov), que no se condicen con la extensión de las novelas en sí, saturados de encuentros, desencuentros, "diálogos en el umbral", multitud de peripecias, prisas, desesperación. Los plazos son apocalípticos, se está siempre a las puertas de una catástrofe, del tiempo final, y toda esta crispación halla su reflejo en la voz.

Hacia las seis se halló en el embarcadero del ferrocarril de Tsárskoie Seló. El aislamiento pronto se le volvió insoportable; un nuevo impulso ganó ardientemente su corazón, y al instante con una luz brillante se alumbró la tiniebla en la cual su alma se angustiaba. Sacó un boleto a Pávlovsk y con impaciencia se apuró a marchar; pero, desde luego, algo lo perseguía, y era la realidad, no la fantasía, como quizá él era inclinado a pensar. Casi ya sentándose en el vagón, de repente tiró el boleto recién sacado al suelo y salió de la estación afuera, turbado y pensativo. Cierto tiempo después, en la calle, de repente fue como si algo le viniera a la mente, como si inopinadamente algo hubiera tomado en cuenta, muy extraño, algo que ya de largo lo intranquilizaba. De repente le ocurrió pescarse conscientemente en una ocupación, en la que hacía rato estaba, pero que había seguido sin advertir hasta este instante mismo: he aquí que ya hacía varias horas, ya incluso en el "Libra", y al parecer incluso antes del "Libra", él cada tanto y de repente comenzaba como si fuera a buscar algo alrededor. Y lo olvida, incluso por un rato, media hora, y de repente de nuevo se da vuelta con intranquilidad y busca alrededor. ${ }^{11}$ (El idiota, parte II, capítulo V)

$11 \mathrm{~K}$ шести часам он очутился на дебаркадере Царскосельской железной дороги. Уединение скоро стало ему невыносимо; новый порыв горячо охватил его сердце, и на мгновение ярким светом озарился мрак, в котором тосковала душа его. Он взял билет в Павловск и с нетерпением спешил уехать; но, уж конечно, его что-то преследо- 
Dostoievski cuenta mientras cavila, y así es como - al paso - acentúa, modaliza, insiste, duda: son más sensaciones físicas que "enunciado", es decir, mímica. Lo que sucede, por otra parte, no está aorísticamente cerrado, en el illo tempore propio del discurso narrativo, sino que está sucediendo ahora, en un presente en el cual coinciden el personaje, el narrador y el lector. (Quedaría para otro trabajo indagar en la relación entre la voz concreta del hombre Fiódor Dostoievski, de la cual aparecen menciones en memorias de sus contemporáneos, y su rastro en la escritura).

Finalmente, una reflexión sobre el lenguaje de Kotlován ("La excavación"), de Andréi Platónov. Los especialistas rusos en literatura coinciden en señalar que es una obra "imposible de traducir", que sería muy difícil hallar en otras lenguas correspondencias con aquello que ellos leen en el original. Buena parte de esta consideración se deriva sin duda del famoso posfacio de Iósif Brodski a la primera traducción de la obra al inglés, donde habla de la expresión, en el texto platonoviano, de una lengua - la lengua soviética - "que se ha vuelto capaz de engendrar un mundo ficticio y que ha caído en una dependencia gramatical de aquel"; es la lengua del callejón sin salida, la lengua que "jadea en modo subjuntivo y comienza a gravitar hacia categorías y construcciones fuera del tiempo, a consecuencia de lo cual incluso en los simples sustantivos el suelo se hunde bajo los pies" (Бродский, 1973). Concretamente, en Platónov encontramos extrañamientos sintácticos y semánticos: palabras combinadas un poco al acaso con otras, a menudo sacadas de su serie habitual o reemplazadas por perífrasis, cuando no fugan a la hipérbole, provenientes ya de un léxico libresco, de registros populares, de la lengua

вало, и это была действительность, а не фантазия, как, может быть, он наклонен был думать. Почти уже садясь к вагон, он вдруг бросил только что взятый билет на пол и вышел обратно из воксала, смущенный и задумчивый. Несколько времени спустя, на улице, он вдруг как бы что-то припомнил, как бы что-то внезапно сообразил, очень странное, что-то уж долго его беспокоившее. Ему вдруг пришлось сознательно поймать себя на одном занятии, уже давно продолжавшемся, но которого он всё не замечал до самой этой минуты: вот уже несколько часов, еще даже в «Весах», кажется даже и до «Весов», он нет-нет и вдруг начинал как бы искать чего-то кругом себя. И забудет, даже надолго, на полчаса, и вдруг опять оглянется с беспокойством и ищет кругом. (Достоевский, 2014, 233) 
burocrática. Es la lengua de los iuródivy, los débiles mentales, los locos que ven la verdad. $\mathrm{O}$, como dijo alguien por allí, la de los "idiotas pensantes":

Prushevski se sentó en un banquito junto a la oficina. Así se sentaba él otrora junto a la casa del padre. Los atardeceres de verano no cambiaron desde entonces, y a él lo complacía sentarse a observar los que pasaban; algunos le gustaban, y él lamentaba que no todas las gentes se conocieran entre sí. Un mismo sentimiento estaba vivo y triste en él hasta hoy: alguna vez, en un igual atardecer, delante de la casa de su infancia había pasado una muchacha, y él no podía recordar su rostro ni el año de ese hecho, mas desde entonces se fijaba en todos los rostros femeninos y en ninguno había reconocido a aquella que, desaparecida, seguía siendo su única amiga y tan cerca pasó sin detenerse. ${ }^{12}$

Pero algo no observado, o al menos no acentuado en las lecturas de Kotlován, es la prosodia envolvente que arrastra hacia su declamación, y cuya lógica también interviene en la tirantez sintáctica y semántica de las frases. Sus párrafos invitan a ser escandidos, llaman la atención sobre los períodos que los constituyen, adquiriendo así lo que Iuri Tyniánov distingue como dinamización del material discursivo - rasgo para él determinantemente inherente a los versos - , donde todos los elementos del discurso quedarían subordinados a una rítmica (más que a la organización sintáctica y el sentido) (Tiniánov, 2010, 65 y ss.). Vladímir Maiakovski, en su extraordinario artículo "¿Cómo hacer versos?", señala que el ritmo es una forma de energía, y que él compone a partir de un "retumbo rítmico" donde va dejando caer las palabras. Dice a propósito de la composición de su poema "A Serguéi Esenin":

Al inicio, la poesía de Esenin barbotea aproximadamente como sigue:

\footnotetext{
12 Прушевский сел на лавочку у канцелярии. Так же он сидел когда-то у дома отца. Летние вечера не изменились с тех пор,- и он любил тогда следить за прохожими мимо; иные ему нравились, и он жалел, что не все люди знакомы между собой. Одно же чувство было живо и печально в нем до сих пор: когда-то, в такой же вечер, мимо дома его детства прошла девушка, и он не мог вспомнить ни ее лица, ни года того события, но с тех пор всматривался во все женские лица и ни в одном из них не узнавал той, которая, исчезнув, все же была его единственной подругой и так близко прошла не остановившись. (Платонов, 2007, 479)
} 
ta-ra-rá/ ra-rá / ra, ra, ra, rá / ra rá /

ra-ra-rí / ra ra ra / ra ra / ra ra ra ra /

ra-ra-ra / ra-ra ra ra ra ra ri /

ra-ra-ra / ra ra-ra / ra ra / ra / ra ra.

Después vienen las palabras:

"Vy ushlí ra ra ra ra ra $v$ mir inói

Moyet byt, letite ra ra ra ra ra ra.

Ni avansa vam, ni baby, ni pivnói,

Ra ra ra / ra ra ra ra / triézvost"'. (Maiakovsky, 1974, 69)

Tal retumbo rítmico fue lo que guio fundamentalmente mi traducción de un texto tan particular como Kotlován, al subordinar la selección lexical y la organización sintáctica a la prosodia del original, sobre cuyo esqueleto iban acomodándose las frases en castellano. Ello tendría una especial pertinencia en el relato de Platónov, pero - como señalaba al principio aplicar el oído al texto es lo que ha representado desde aquel primer Dostoievski, con mayor o menor énfasis, mi reaseguro fundamental a la hora de traducir. Por supuesto que partir de aquí, y al igual que aquello que llamamos en el canto "segunda voz", será fatal que a la voz del original haga coro la nuestra, ya que con ella, por sobre otros aspectos, vamos al encuentro del autor y su obra.

Así, en nuestro artículo hemos perseguido dos objetivos: reparar en la incidencia de la voz - y todo lo que de ella se deriva - en creadores señeros de las letras rusas, a la vez que proponer la persecución de esa voz en los originales como clave de traducción.

\section{Referencias bibliográficas}

BARTHES, Roland. El grano de la voz. Entrevistas 1962-1980. Buenos Aires: Siglo XXI. 2005.

DOLAR, Mladen. Una voz y nada más. Buenos Aires: Manantial. 2007. 
MAIAKOVSKY, Vladimir. Poesía y revolución. Barcelona: Península, 1974.

MESCHONNIC, Henri. Ética y política del traducir. Buenos Aires: Leviatán. 2009.

TINIÁNOV, Iuri. El problema de la lengua poética. Buenos Aires: Dedalus. 2010.

VOLÓSHINOV, Valentín. El marxismo y la filosofía del lenguaje. Buenos Aires: Godot. 2009.

ГОГОЛЬ, Н.В. Статьи [т. 8]. Полное собрание сочинений [В 14 т.] (1937-1952). Москва/Ленинград: АН CССР. 1952. Disponible en http://feb-web.ru/febupd/gogol/default.asp?/febupd/ gogol/texts/ps0/ps0.html [Gógol, Artículos (tomo 8). Obras completas (en 14 tomos)]

ГОГОЛЬ, Н.В. Мертвые души. Москва: Художествнная Литература. 1993. [Gógol, Almas muertas.]

ГОГОЛЬ, Н.В. Вечера на хуторе близ Диканьки. Миргород. Москва: АСТ. 2009. [Veladas en una granja cerca de Dikanñka.] ДОСТОЕВСКИЙ, Ф.М. Братья Карамазовы. Москва: Эскмо. 2005. [Dostoievski, Los hermanos Karamázov.] Платонов А.П. Чевенгур. Котлован. Рассказы. Москва, Эксмо. 2007. [Platónov, Chevengur. Kotlován. Cuentos.]

ТУРГЕНЕВ, И.С. «Гоголь». 1952. Disponible en http://feb-web. ru/feb/gogol/critics/gvs/gvs-531-.htm [Turguéniev, "Gógol”.]

ЭЙХЕНБАУМ, Б.М. «Иллюзия сказа». Сквозь литературу // Вопросы поэтики; Вып. 4. 1924. Disponible en http:// books.e-heritage.ru/book/10071177 [Eichenbaum, "La ilusión del skaz". En A través de la literatura.]

Recebido em: 26/08/2020

Aceito em: 18/11/2020

Publicado em dezembro de 2020 